\title{
De la naturaleza a la tecnoespecie: La proyección antropotécnica de la condición humana
}

\author{
From nature to technospecies: \\ The anthropo-technical projection \\ of the human condition
}

\author{
JORGE ENRIQUE LINARES SALGADO
}

Universidad Nacional Autónoma de México

\section{RESUMEN}

La humanidad evolucionó durante milenios para desarrollar unas características biológicas, culturales, cognitivas y simbólicas comunes, que han posibilitado la expansión de nuestra especie por toda la Tierra y el desarrollo cultural y tecnológico de nuestra era. En este artículo exploramos someramente las ideas del ser humano, proyecciones simbólicas de lo que hemos aspirado a ser, y nos concentramos en la idea moderna autopoiética o de autotransformación, que en nuestro tiempo está postulando la necesidad y posibilidad de una transmutación radical de nuestra especie mediante las bio y neuro tecnologías, generando lo que se denomina «antropotecnologías». El transhumanismo o movimiento de automutación radical de la especie humana nos conducirá, probablemente, a un objetivo que alterará la historia de la humanidad y que, por tanto, debe ser revisado y evaluado desde una perspectiva filosófica y ética por sus profundas consecuencias.

\section{PALABRAS CLAVE \\ NATURALEZA HUMANA, BIOTECNOLOGÍA, TRANSHUMANISMO, ANTROPOTECNOLOGÍAS}

\begin{abstract}
Humanity evolved for millennia to develop common biological, cultural, cognitive, and symbolic characteristics, which have made possible the expansion of our species throughout the earth
\end{abstract}


and the cultural and technological development of our age. In this article we explore briefly the ideas of the human nature, which have been symbolic projections of what we have aspired to be, and we focus on the modern «autopoietic» idea or self-transformation idea, which in our time is postulating the need and possibility of a radical transmutation of our species through bio and neuro-technologies, generating what is called «anthropo-technologies». The transhumanism or radical self-transformation movement of the human species will probably lead us to an goal that will alter the history of humanity and, therefore, should be reviewed and assessed from a philosophical and ethical perspective by its profound consequences.

KEY WORDS

HUMAN NATURE, BIOTECHNOLOGY, TRANSHUMANISM, ANTRHOPO-TECHNOLOGIES

\section{INTRODUCCIÓN}

NUESTRA ESPECIE ha destacado por sus capacidades de supervivencia y de sorprendente movilidad migratoria para lograr colonizar prácticamente todos los rincones de la Tierra. A lo largo de este viaje también ha emigrado de su condición natural para forjar un nuevo ethos y un status técnico, simbólico e histórico, para transformarse a sí misma en un híbrido bio-técnico-cultural que ha hipertrofiado algunos de sus rasgos comunes con los demás seres vivos hasta alcanzar una naturaleza singular.

Este éxodo humano, que se remonta cientos de miles de años en el pasado, ha sido también un extraordinario viaje en busca de su propia identidad. A lo largo de su evolución, los humanos han querido confeccionarse una identidad para acabar de reconocerse a sí mismos; identidad que han pretendido fijar tatuándosela en la piel o plasmándola en una serie de símbolos para verse reflejados en ellos; pero el esfuerzo ha resultado, en gran medida, infructuoso. En nuestros tiempos ha cobrado fuerza la idea de que ese tatuaje está hecho de signos genómicos, que está cifrado en el código de información genética de las moléculas de la vida; pero mientras más se avanza en el estudio del genoma, más nos perdemos en el abismo de un jeroglífico que encierra el misterio de nuestro origen arcano. Quizá sea el genoma ese espejo enterrado en nuestro interior que nos niega una imagen clara o definitiva.

En efecto, el ser humano ha escudriñado su genoma y ha intentado anticipar y adivinar su suerte futura, como antes lo hacía hurgando en las entrañas de animales que destazaba o mirando las estrellas. Ese código genético nos ha revelado nuestro profundo vínculo con los demás seres vivos, ha reafirmado nuestra pertenencia a la comunidad biótica de la Tierra, pero nos oscurece también nuestro destino: lo que vemos es una configuración abierta, polimórfica, pero ambigua y frágil. No es un código de una sola dimensión que pueda leerse linealmente. Pero ¿acaso hemos despertado ya del sueño del determinismo genético para darnos cuenta de que nuestra identidad no sólo está hecha de genes? 
Si es así, no tuvimos que esperar a que ningún filósofo nos despertara, parece más bien que la intuición que percibimos sobre la extrema complejidad de lo humano nos hacer dudar de nueva cuenta sobre nuestro origen y nuestro destino.

A pesar de lo mucho que se ha avanzado en el estudio de nuestro genoma, este descubrimiento asombroso no ha podido descifrarnos nuestra identidad, pero nos ha reflejado la imagen de un poder tecnológico sin precedentes, capaz de transfigurar la estructura genética de todas las especies. Y ciertamente, en la medida en que mayor conocimiento adquirimos de las estructuras genéticas, mayor es la confianza en nuestro poder tecnológico para transformarla, pero no necesariamente para comprenderla a cabalidad.

Lo que resulta claro en nuestros días es que ya no podemos pensar la condición humana como una sustancia inmutable y ajena al devenir histórico, como lo hizo la filosofía durante mucho tiempo, sino como un proceso inacabado y en una constante proyección ideal, pues la imagen simbólica de la humanidad es más un proyecto de lo que aspiramos a ser que una realización terminada. Somos una especie natural emparentada con todas las demás, pero una especie que se ha hipertrofiado y que tiene voluntad de hybris; que sobrepasa todos sus límites, que ha saltado del continuum de la naturaleza y que ha desafiado sus propias contenciones, cualidades que se manifiestan tanto en los logros más sublimes del pensamiento, la técnica y de la expresión artística como en los actos más violentos y demenciales de los seres humanos contra sus semejantes y contra otros seres vivos.

Ahora bien, quizá lo que nos caracteriza es que somos una especie que busca su identidad o que se afana en huir de ella: emergimos con la tenue conciencia de un destino común que ahora se nos vuelve a hacer difuso. Somos una humanidad peregrina — homo viator - en busca de su propio ser, pero quizá nos hayamos lanzado a la caza de una empresa irrealizable: nos hemos topado, una y otra vez, con una condición humana inestable, vulnerable y capaz de destruirse a sí misma, ya sea mediante la barbarie y el genocidio o mediante el ecocidio perpetrado contra el medio ambiente.

La imagen autopoiética de la humanidad que predomina en nuestros tiempos tecnocientíficos se fundamenta en esa voluntad de hybris que desea traspasar todos los límites que la naturaleza nos había impuesto, para poder saltar así hacia un estado posnatural y plenamente artefactual de la condición humana. Nos volveremos, ¿ahora sí?, una tecnoespecie.

Por ello, la imagen simbólica de lo humano, más que una insignia acabada, es un proyecto existencial de lo que la humanidad aspira a convertirse; constituye el efecto de una voluntad colectiva de parecernos a la imagen que forjamos de nosotros mismos (esta imagen estaba hecha de conocimientos científicos, de viejos mitos religiosos y de relatos humanísticos). Y la imagen que hoy predomina es la de una species technica (Hottois, 2002) y el medio 
es la antropotécnica (Goffette, 2006); es decir, una especie que se construye y remodela a sí misma, en la medida precisamente en que transforma y reconfigura al resto de las especies y de los ecosistemas con los que convive.

\section{LAS CUATRO CONCEPCIONES HISTÓRICAS DE LO HUMANO}

La imagen simbólica de la humanidad (expresada en el pensamiento, las artes, los mitos y los relatos) ha tenido un largo recorrido histórico. En la civilización occidental, la idea del hombre (Nicol, 1977), el espejo enterrado de la identidad, se ha expresado en cuatro formas principales: a) la concepción logocentrista (el ser humano como viviente dotado de logos) típica del humanismo antiguo, ${ }^{1}$ b) la concepción espiritualista (alma racional e inmortal y cuerpo finito) o concepción «sobrenaturalista» de fuerte influencia judeocristiana, que acentúa el dualismo entre el espíritu y el cuerpo fenoménico; c) la concepción naturalista o imagen naturalizada, derivada de la revolución científica moderna, que engendró figuras como la del «hombre máquina» de La Mettrie y del mecanicismo moderno, que no hemos abandonado del todo; d) la imagen del hombre como ser carente, como ser sin esencia, inacabado y defectuoso biológicamente, que debe sobreponerse mediante la inteligencia técnica y la autopóiesis, idea que predomina en nuestro tiempo y que tiene sus orígenes en el Renacimiento. A ella contribuyó durante el siglo XX el existencialismo y, en parte, el historicismo (Nicol, 1981): todo lo humano no es más que producto histórico-social. ${ }^{2}$

Para la concepción cristiana predominante en Occidente, vía el neoplatonismo, el alma es de carácter sobrenatural e inmortal, así que podríamos decir que la dualidad típica de esta concepción termina inclinándose hacia una imagen del ser humano transnatural o sobrenatural (al menos como una aspiración). La humanidad es justamente aquello que está más allá de la naturaleza biológica

1 El logocentrismo apuesta por una superación o transformación «simbólica» de nuestros defectos y limitaciones humanos; la ética, la política y las virtudes son los instrumentos para luchar contra la contingencia y la imperfección natural. El ser humano puede ser moldeado y formado mediante la cultura discursiva y dianóica; en alemán la cultura se denomina Bildung, que significa «construcción». Esta idea clásica de que la cultura forma lo humano a partir de una materia prima natural y animal que debe ser transformada o «humanizada» es la tesis central de la tradición humanística.

2 Esta concepción también podría caracterizarse como «autopoiética» pues consolida la idea de que la naturaleza humana está abierta e inacabada, pero los humanos son capaces de producirla. El dogma tanto del existencialismo como del historicismo podría resumirse en la famosa tesis orteguiana: «el hombre no tiene naturaleza, tiene historia», sea que se conciba como historia colectiva o historia individual y singular, que cada uno debe forjar. Es la idea que inaugura la famoso Oración por la dignidad del hombre de Pico de la Mirandola. 
y que, emergiendo de la vida, tiende o aspira hacia la inmortalidad, como ya lo señalaba Platón con la figura del alma alada en el Fedón (Platón, 2011).

Descartes convierte al alma en sustancia pensante (res cogitans), la dualidad humana se tensa al máximo: el hombre es dos sustancias a la vez, una finita y contingente y otra inmortal e indestructible. Kant trata de resolver el problema de este dualismo ontológico sin lograrlo: en lugar de la dualidad de dos sustancias, afirma que el ser humano pertenece a dos mundos distintos: al mundo fenoménico y al mundo nouménico; en uno está determinado por las causas naturales, en el otro es plenamente libre y responsable de su libertad (autónomo). Desde el punto de vista del mundo fenoménico, el ser humano es objeto de estudio de la antropología (y de la biología, por tanto); desde el segundo, es una cosa en sí incognoscible, sólo inteligible desde la razón práctica, que postula la idea (incomprobable empíricamente) de lo humano como sujeto moral autónomo y libre.

En los inicios del historicismo, Herder atisba en el lenguaje el medio por el que los seres humanos resuelven sus «deficiencias» biológicas. El hombre es un «Mängelwesen», un ser de carencias. En la antropología moderna esta idea del ser carencial se refuerza y se compensa con una reaparición del mito del origen de la técnica que ya se hallaba en el Protágoras de Platón. Ya que el hombre, por culpa de Epimeteo, no recibe cualidades corporales para defenderse y sobrevivir, más que su inteligencia, ésta lo lleva a desplegar su actividad técnica para protegerse y construirse un mundo propio dentro de la naturaleza ambiente. Ya en el siglo XX, Arnold Gehlen parte de la idea de un «estado carencial» para afirmar que lo propio de lo humano es la capacidad de salir de este estado mediante la acción técnica para dominar el ambiente. Ortega y Gasset reforzará la idea con la tesis de la construcción técnica de una «sobrenaturaleza humana» (Ortega y Gasset, 2015).

Puede observase, a pesar de notables diferencias, que todas las concepciones históricas de lo humano enfatizan la dualidad entre el carácter natural de nuestra especie y un algo más de no-natural o sobrenatural, espiritual, autocreado y agregado a la naturaleza, técnico o histórico, que nos distingue del resto de los seres vivos; es decir, lo que es común a todas ellas es una tensión entre el reconocimiento de la pertenencia de lo humano a la naturaleza y, a la vez, su extrañeza. Esta es la tesis de la «excepcionalidad humana» que ha explorado Jean-Marie Schaeffer (Schaeffer, 2009). En la idea misma de naturaleza humana puede inclinarse la balanza de un lado o hacia el otro: humanidad natural como especie o naturaleza humanizada (transmutada culturalmente). Asimismo, todas estas concepciones apuestan por una capacidad de trascendencia de esa ambigua condición humana; ya sea mediante una vinculación con lo transnatural para alcanzar la redención y/o la inmortalidad (en el sentimiento religioso y místico), o mediante la superación material, técnica, y no sólo sim- 
bólica, de la propia condición biológica para lograr un estado de perfección transhumana (ideas preconizadas por la otra especie de «religión» o creencia dogmática contemporánea en el progreso tecnocientífico).

Pero el proceso no ha terminado ahí, como veremos, ahora la humanidad se reconstruye la imagen de sí misma como un ciborg (Haraway, 1995) o como una transición hacia el super-hombre tecnificado en los proyectos del transhumanismo (Savulescu \& Bostrom, 2009), una humanidad biomejorada tecnológicamente (Diéguez, 2017).

Una definición genérica del ser humano, puramente descriptiva, podría ser la siguiente de Edgar Morin (Morin, 2003), pues la unidad genérica de nuestra especie acusa varios rasgos enraizados biológicamente: el ser humano es un animal vertebrado, mamífero y primate, pero es un hipermamífero de corteza cerebral hipertrofiada que ha desarrollado y ampliado sus emociones y sentimientos, inteligencia, memoria y afectividad para pensar/imaginar, amar/ odiar, gozar/sufrir intensamente, de manera individual y también colectiva. Es un animal hipersexuado (todo su cuerpo es erógeno y no está sujeto a periodos restringidos de celo). Es también un hiperprimate caracterizado por su bipedismo, visión periférica, aguda inteligencia técnica, organización social estratificada, su doble y extrema capacidad racional/demencial y, si creemos a Aristóteles, también por su natural afán de conocer. El pensamiento, el lenguaje, la imaginación, los mitos, ritos y ensoñaciones, en suma, la hipertrofia social de las capacidades de la corteza cerebral distingue al humano entre el resto de los vivientes. ${ }^{3} \mathrm{El}$ ser humano ha sido producto de una metamorfosis ontogénica que se repite filogenéticamente en cada individuo: cerebralización (derivada de una neotenia), bipedación, manualización, verbalización, juvenilización, ${ }^{4}$ complejización social (simbólica y lingüística, política, operativa y técnica), axiologización de la conducta y autorreflexión moral e introspectiva; pero también regresión egocéntrica, neurótica, barbarización, escisión mental, demencialización, tribalización, violencia colectiva organizada y exclusión de todo aquel que parezca otro, extraño, amenazante o que se aparta de la norma social.

Por tanto, unos cuantos rasgos conforman nuestra identidad simbólica: libertad y autonomía, autoconciencia y sensibilidad moral; ampliada capacidad emocional y sentido del tiempo y de la finitud. Pero debemos preguntarnos, una vez más, cuáles son los rasgos que definen la humanidad de nuestra especie

3 Nuestra memoria se amplifica también social e históricamente. Poseemos un sentido amplio de la temporalidad y de la muerte, a la que intentamos desafiar o negar mediante rituales, cultos mortuorios, ataúdes, embalsamamientos, pirámides y construcciones simbólicas como las religiones, las ideologías, obras de arte y todo tipo de artefactos simbólicos con los que creemos sublimar la conciencia de la finitud.

4 Ampliación de la infancia y la juventud que posibilita la plasticidad cerebral para aprender y adaptarse a una o varias culturas y lenguajes. 
biológica. Son aquellas capacidades y libertades básicas las que posibilitan la variabilidad y la individuación de la existencia, y las que constituyen el fundamento de derechos universales. ${ }^{5}$ Me aventuraré a realizar una descripción somera y empírica de los rasgos más relevantes de la naturaleza humana que nos definen y que deberíamos preservar dentro de un rango estable de variaciones técnicas y culturales:

1) La natalidad-mortalidad: la conciencia de la finitud y de la contingencia determina en gran medida nuestra imagen simbólica, así como el reconocimiento universal de la condición humana. Humano significa aquel ser que es consciente de haber nacido y consciente de que tiene que morir. ${ }^{6}$

2) Una corporalidad natural recibida (hasta el momento no diseñada ni construida técnicamente): el cuerpo es la fuente de nuestras potencialidades, pero también de nuestros límites y vulnerabilidades dados por la naturaleza evolutiva. Todos hemos recibidos un cuerpo biológico que, hasta ahora, no ha diseñado nadie ni intervenido previamente de un modo sustantivo. No hemos sido creados ni fabricados, hemos sido engendrados mediante procesos naturales de reproducción que, aun con las actuales técnicas de reproducción asistida, no han cambiado este hecho crucial. Este es el fenómeno que conduce a Habermas a sostener la tesis de que la dotación genética recibida aleatoriamente por cada uno de nosotros constituye la ética de la especie (Habermas, 2002). Desde luego, la experiencia del cuerpo está construida culturalmente, pero es una constante biológica que establece los límites de lo que puede ser vivido, y que condiciona las necesidades básicas, así como las capacidades y potencialidades que humanizan la existencia. Si en el futuro un robot inteligente (o quizá un mamífero superinteligente modificado técnicamente) escribiera un artículo titulado «¿Cómo se siente ser un humano»?, en clara respuesta a aquél de Thomas Nagel, tendría que basarse descriptivamente en nuestras características corporales comunes y dadas de manera natural para intentar imaginarse nuestras experiencias cognitivas y valorativas. (Nagel, 2000, pp. 274-296).

5 Las capacidades humanas básicas se han definido como: poder vivir hasta el final una vida humana completa, tanto como sea posible, poder tener buena salud; estar suficientemente alimentado; tener alojamiento adecuado; tener oportunidades de satisfacción sexual; poder desplazarse de un lugar a otro, poder evitar el dolor innecesario y perjudicial, así como obtener experiencias placenteras, poder usar los cinco sentidos, imaginar, pensar y razonar, poder vincularse a personas y cosas fuera de nosotros mismos, poder formarse una concepción del bien y comprometerse en una reflexión crítica acerca de la propia vida, poder vivir para y con otros, reconocer y mostrar preocupación por otros seres humanos (por animales y otros seres vivos y la naturaleza en general), poder reír, jugar, disfrutar de actividades lúdicas. Véase Nussbaum, M., /Sen, A. (coords.), la calidad de vida, FCE, México, 1996.

6 ¿Qué pasaría con robots de IA que desarrollan también conciencia de $s u$ natalidad y su mortalidad? Este rasgo dejaría de ser solamente humano. 
3) La mutabilidad y la vulnerabilidad: el cuerpo humano es vulnerable y está expuesto a mutaciones genéticas, mentales y culturales, porque es afectado por otros cuerpos mediante la sensibilidad y por ideas mediante el pensamiento y la imaginación. Pero hasta ahora las mutaciones más significativas que ha sufrido la humanidad han sido más bien «simbólicas» que técnicas, el hombre se ha moldeado su propio ser como resultado de un proceso de modificación de la conciencia, pero no todavía de una intervención técnico-operativa en su estructura biológica, genética o neural; la vulnerabilidad y la mutabilidad mantienen al cuerpo humano en un frágil equilibrio con el entorno; diferentes agentes ambientales -naturales o artefactuales-alteran de hecho su conformación genética y el equilibrio fisiológico con el medio ambiente, pues sufrimos mutaciones cada uno de nosotros y en conjunto la especie sigue evolucionando lentamente. Sin embargo, hasta ahora los cambios más radicales se han operado en nuestra conciencia del mundo y en nuestras capacidades cognitivas. Las recientes revoluciones tecnológicas de las TIC, que han creado prótesis cognitivas, están alterando y aumentando más esas capacidades hasta desbordar los límites naturales de nuestra memoria promedio y habilidad para percibir, calcular y procesar datos.

4) La individualidad: cada uno de nosotros es una unidad con su propio cuerpo, siente, padece y ama en "carne propia», por lo que la experiencia corporal es, hasta ahora, insustituible e intransferible. ${ }^{7}$ Aunque el valor social de la individualidad es relativo porque está codificado culturalmente, permanece como base de reconocimiento de una comunidad ontológica entre seres humanos. Somo seres partidos o separados físicamente del conjunto de la especie. Pero simbólicamente nos reconectamos con los demás y con el grupo de formas imaginarias y emocionales. Excepto los siameses, los humanos no vivimos en conglomerados corporales, somos cuerpos individuados. De ahí la experiencia profunda de la soledad, y los trastornos mentales que produce el aislamiento prolongado. Y por ello, todo Robinson Crusoe que vive solo en su «isla» necesita construirse otro, un alter ego; pero de hecho, todos somos robinsones que nos construimos imaginariamente nuestros alter egos, porque «el anthropos es el símbolo del anthropos», como decía Platón en el Banquete (Platón, 2011).

5) La interdependencia social: mediante la corporalidad sensible el sujeto está abierto y vinculado al mundo; es capaz de interactuar y de compenetrarse con otros seres humanos, con otros animales y con la naturaleza entera, mediante sus dispositivos sensoriales y emocionales. Nuestro cerebro es una caja

7 En la serie de TV Black Mirror, en dos capítulos de la cuarta temporada, Black Museum y ArkAngel, se especula con la posibilidad de una transferencia digital directa y en tiempo real de emociones y sensaciones de un sujeto a otro. 
de resonancia emocional de todo lo que sentimos y nos afecta. La empatía y la capacidad de simpatizar, de amar, pero también de odiar y destruir nos definen.

6) La sensibilidad emocional: la interdependencia se funda en la sensibilidad corporal, por la que el individuo es capaz de desarrollar diversos grados de sensaciones y emociones, de tener sentimientos de sociabilidad y de preocupación por la vida de otros seres vivos. Sin estas emociones fundamentales empáticas no habría emociones morales (amor, odio, indignación, sentido de la injusticia, etc.) ni códigos morales de conducta.

7) Las facultades cognitivas: la percepción, la imaginación y el pensamiento. El ser humano es capaz de tener conciencia de su interdependencia con el mundo mediante sus representaciones mentales, es capaz de imaginarse la situación de otros y de anticipar los acontecimientos para planear y orientar sus acciones. La vida humana es proyecto, pero sólo como representación de la conciencia de lo ya vivido, sea que proyectemos un futuro en el que el presente continúa y se refuerza, sea que proyectemos un futuro utópico o distópico a la medida de nuestros afanes y anhelos o miedos y angustias.

8) Sentido y conciencia éticos: el hombre es capaz de valorar las cosas para orientar su vida, es capaz también de evaluar y elegir entre opciones para realizar un modelo de vida buena. Los valores están condicionados histórica y culturalmente, pero es una constante humana la necesidad de valorar y de elegir entre posibilidades que se despliegan en la existencia.

Por otra parte, cualidades especiales distinguen al individuo humano de cualquier otro ser vivo: a) las capacidades simbólicas de articular un lenguaje y de armar representaciones del mundo; la racionalidad de dichas representaciones y la habilidad de comunicarlas; el hombre es el ser de la expresión (Nicol, 1974) no sólo por su habilidad para representarse lo real, sino porque mediante dichas representaciones y expresiones conforma un mundo compartido intersubjetivamente; de ello deriva la capacidad de autoconciencia, de compartir las verdades que descubre, de poseer fines y de proyectar su vida hacia el futuro, así como de dar razón del mundo. Como dice Eduardo Nicol (Nicol, 1974) el hombre expresa porque tiene que morir. La expresión humana es herencia recibida y legado para las generaciones futuras.

b) Dado que la representación que nos hacemos del mundo no puede ser absoluta, nuestras ideas están sometidas a la duda y a la interrogación constantes; mientras que las decisiones, a la ambivalencia y la incertidumbre en la que actuamos, porque tenemos que elegir entre diversas alternativas; el hombre es, como decía Nicol, el ser de la posibilidad, que fundamenta la condición ética, por la cual deliberamos y decidimos, aun cuando no haya opciones viables.

c) La conciencia de la limitación de nuestras capacidades cognoscitivas está fundada en la vivencia corporal de la finitud de nuestro ser y en el sentido de una temporalidad irreversible, condiciones para la formación de una auto- 
conciencia histórica, que son el germen de la responsabilidad por el futuro; el hombre es un ser consciente de su historia y del destino de su ser. No obstante, la ignorancia connatural sobre nuestro propio destino es la condición de la libertad de acción; el hombre es un ser libre y autónomo porque no puede predeterminar su destino.

Por tanto, el sentido ético de la existencia humana se funda en la conciencia de la finitud, la contingencia y la indeterminación, la libertad y la vulnerabilidad, y la esencial interdependencia de nuestro ser, que emanan de la imagen de la corporalidad que hasta el momento hemos moldeado simbólica y culturalmente mediante el lenguaje y el discurso, a partir de los límites de una configuración corporal dada, con todas sus restricciones y potencialidades naturales.

\section{LA PRÓXIMA MUTACIÓN BIOARTEFACTUAL DE LA IMAGEN DE LO HUMANO}

La revolución biotecnológica de nuestro siglo se propone dominar el territorio de la «naturaleza natural» humana y de la biosfera entera, conservada hasta ahora en unidad biológica y diversidad cultural, para transmutarla de un modo radical e irreversible en una diversificación biológico-genética-neural artefactual y en una paradójica uniformidad cultural. Por ello, ha surgido una futurista «antropotécnica» (Goffette, 2006) que ya despunta en la cirugía plástica, selección de embriones por reproducción asistida, farmacogenómica, neurofarmacología, cirugías y tratamientos de cambio de sexo y otras prácticas «para-médicas» con fines no sólo remediales (sino eugenésicos), que representan desde ahora un verdadero desafío ético-filosófico, pero también estético-simbólico. Porque antes de que los proyectos eugenésicos transhumanistas (Diéguez, 2017) sean una realidad efectiva (con las sorpresas que seguramente depararán), han generado representaciones sociales inquietantes y controversiales. Esas representaciones constituyen en general lo que yo denomino la estética de la biotecnociencia contemporánea, precedida por el bioarte (con obras de autores como Eduardo Kac, Orlan o Stelarc) (González-Valerio, 2014). En particular, la estética de las biotecnociencias contemporáneas está generando una matriz global de imágenes sociales del mundo feliz de la reconfiguración total de la naturaleza, y está redefiniendo los marcos cognitivos y axiológicos en los que actúan las nuevas generaciones de seres humanos, que ya se sienten y se miran a sí mismos como mutantes transhumanos, sin serlo todavía.

En el mundo tecnológico contemporáneo los humanos y los demás seres vivos se han convertido en materia prima de transformación. Sus cuerpos y sus condiciones ambientales de vida han sido transfigurados no sólo de manera material sino también simbólica, en formas de virtualizaciones informáticas y proyecciones estéticas. Los seres vivos, además de seguir siendo alimento, se han convertido, figurativa y realmente, en fuente de energía (biocombustibles), de nuevos biomateriales, conocimientos («organismos modelo»), obras de arte 
in vivo, paradigmas y fuente de información para modelar y construir nuevos bioartefactos. Esta es la gran transformación biotecnológica que podemos esperar en la era de la bioartefactualidad (Linares \& Arriaga, 2016), pues se caracteriza por la nueva y poderosa capacidad técnica de transmutar la materia viva, así como por introducir cambios sustanciales en las representaciones sociales y concepciones teóricas sobre la naturaleza, los seres vivos y nuestra propia naturaleza humana.

La idea autopoiética y carencial del ser humano se ha convertido en los últimos años en un proyecto tecnocientífico de automutación de la naturaleza humana. En esta proyección se avizora que la potencialidad tecnológica para modificar estructuralmente el cuerpo humano y para revolucionar la relación entre el individuo y su medio tendrá repercusiones radicales en la historia de nuestra especie. Esta confianza en la tecnociencia ha dado origen a un nuevo híbrido, paradójico y poderosamente simbólico, de la idea de lo humano, que se caracteriza por refundar la imagen autopoiética en un movimiento milenarista de transhumanismo, que proclama el fin de las ambigüedades y defectos de nuestra condición biológica, sujeta hasta ahora a la evolución natural (BBVA \& Open Mind, 2016). Dejaremos la era de la naturaleza humana, proclaman los transhumanistas como Nick Bostrom, para arribar a la era de la producción o fabricación técnica de lo humano (rediseño biotecnológico de nuestra especie, para entrar plenamente en una nueva era de la evolución y la selección artificiales).

Estas proyecciones transhumanistas han suscitado ya en el imaginario social, tanto en los debates académicos como mediáticos, escenarios posibles que van de lo apocalíptico hasta lo más «integrado» al sistema tecnoeconómico actual, reforzando el miedo o la confianza un tanto irreflexiva sobre el futuro biotecnológico de la humanidad. Los más entusiastas proclaman que el ser humano conquistará el poder de controlar y reconfigurar (o literalmente fabricar) su corporalidad y, en especial, su cerebro, con el fin de autorrediseñarse para expandir a voluntad sus facultades y alcanzar así un estado de pleno bienestar. Pero los transhumanistas siempre dejan de lado o minimizan la cuestión éticopolítica del incremento de la desigualdad social entre los «genenriquecidos», como los denomina Matt Ridley (Ridley, 2004), y los miles de millones que permanecerán muy probablemente en «estado natural» o empobrecidos técnicamente, como de hecho ya sucede si comparamos el acceso a las tecnologías médicas disponibles. Por eso, estas proyecciones transhumanistas han ayudado a reavivar - sin quererlo- los problemas y dilemas de la justicia distributiva, la tolerancia y la protección de los derechos humanos, temas políticos muy urgentes y candentes en el presente. 


\section{LA PRESERVACIÓN DE LA NATURALEZA HUMANA}

De vuelta al tema de la imagen identitaria de nuestra especie, por primera vez podemos preguntarnos, con cierta seriedad (aunque no sé si con serenidad), si la humanidad seguirá siendo lo que siempre ha sido: una especie natural producto de la evolución, pero sin que podamos resolver todavía el acertijo del significado de nuestro propio ser bio-técnico-cultural. Nuestra especie se visualiza a sí misma tomando el mando de su propia evolución y asumiendo el poder para modificar a todas las demás especies; pero esta potestad, en sí misma tentadora y deslumbrante, podría conducirnos a una peligrosa ambivalencia si, al mismo tiempo, no nos hiciera capaces de comprendernos y de autocontenernos. La estética tecnocientífica de la autopóiesis requiere, ahora más que nunca, de una nueva ontología y de una consistente crítica ética, estética y política.

Quizá deberíamos apostar por la permanencia de una comunidad ética que conserve su unidad biocultural y su dinámica identidad simbólica; es decir, por conservar los rasgos esenciales de la naturaleza humana sin que tengamos por ello que renunciar a muchas de las más esperanzadoras posibilidades de investigación y tratamiento terapéutico y de mejoramiento que la biotecnología podría ofrecer. ${ }^{8}$ De esta manera, podemos conciliar la responsabilidad colectiva por nuestra especie, la precaución para evitar daños mayores irreversibles en nuestros cuerpos y en nuestra dotación genética, la justicia y la equidad en la distribución de los productos biotecnológicos, y finalmente, la protección de la autonomía de todas las personas y comunidades para evaluar y decidir sobre sus propios cuerpos y sus proyectos de vida.

El acrecentado poder tecnológico para transformar de un modo radical la naturaleza humana representa ahora un verdadero desafío ético-filosófico. La configuración genotípica y fenotípica (y principalmente neurológica) del ser humano podría ser el objeto de una profunda transformación tecnológica, sin precedentes en la historia. Se impone por eso la necesidad de una nueva empresa colectiva de meditación ética y de investigación científica multidisciplinaria que reconstruya la imagen poliédrica de nuestro ser.

Así pues, la tecnociencia está adoptando fines eugenésicos y transhumanos, pues posibilitaría la intervención y manipulación sobre la base material, biológica y ambiental, de la condición humana. ${ }^{9}$ Estas perspectivas «transhu-

8 Deberíamos avanzar más en el conocimiento y tratamiento de las enfermedades que nos aquejan (cáncer, sida, diabetes, enfermedades cardíacas, enfermedades degenerativas del cerebro, etc.), sólo que, en el campo de la biotécnica, la prudencia y el principio de precaución debe guiarnos para evitar consecuencias negativas irreversibles.

9 Los objetivos de las tecnologías transhumanas serían: a) en primer lugar, la extensión de duración de la vida. De concretarse una posible extensión ilimitada de la vida humana, conservando la salud y la vitalidad, lo que se alteraría radicalmente sería la conciencia de la 
manistas» (aún en fase experimental y quizá meramente utópicas) tienen ya consecuencias de orden ético y político, pues han suscitado el resurgimiento de añejos proyectos eugenésicos y una modificación simbólica de la imagen de lo humano. El individuo podría ser en el futuro reconfigurado genética y neurológicamente para aumentar y potenciar las capacidades físicas, intelectuales, sensoriales, controlar las emociones y los sentimientos más íntimos, e incluso para extender la duración de su existencia más allá de lo imaginable ${ }^{10}$ (BBVA \& Open Mind, 2016). Las más tentadoras posibilidades desembocarían en el

irrevocable finitud de la existencia individual. La extensión de la duración de la vida podría obnubilar nuestro «ser-para-la-muerte». La conciencia de la muerte es un componente esencial de la condición humana que configura muchos otros rasgos de nuestra vida. «La mortalidad es el reverso de la natalidad», como afirmaba Hannah Arendt. b) Ampliación y potenciación de las capacidades intelectuales. La memoria, la capacidad de comprensión y de procesamiento cerebral de información podrían aumentarse de una manera asombrosa mediante transformaciones genéticas, implantes biónicos o con uso de neurofármacos. c) Modificación y potenciación de las funciones y habilidades corporales. En parte, el uso de hormonas, esteroides y otras sustancias en el deporte prefiguran la posibilidad de modificaciones radicales y sintéticas de las capacidades corporales: el ritmo respiratorio y cardiaco, la fuerza muscular, incluso la capacidad de autoregeneración de tejidos o de extremidades enteras, fortalecer el sistema inmunológico, controlar el metabolismo y convertir a nuestro cuerpo en una especie de mónada inmune a los efectos de su medio y a diferentes tipos de enfermedad. d) La modificación y el control de las emociones internas. Eliminar o controlar sentimientos subjetivos negativos y potenciar los positivos (pero también lo contrario). El «dominio de las pasiones» que prescribían los filósofos modernos, quedaría como un recurso obsoleto y poco eficiente. Mediante diversas tecnologías podrían potenciarse las sensaciones de libertad, alegría y bienestar. Fármacos como el Prozac o el Ritalín son un antecedente de las posibilidades que se abrirían en este campo. e) La ampliación de las capacidades de percepción del entorno, así como la extensión de las capacidades sensoriales. La tecnología informática de los biochips, la modificación o sustitución de neurotransmisores, o bien la nanotecnología en conjunción con la ingeniería genética podrían suprimir o controlar las sensaciones vitales más íntimas para modificar a voluntad los procesos de la conciencia y compartirlos con otros o apropiarnos las emociones y pensamientos de otros. El resultado de estas intervenciones alteraría la esencial «ambigüedad de la libertad humana» (como decía Hans Jonas); es decir, el frágil equilibrio entre necesidad, libertad y azar, pues quizá podría llegar a «programarse» la conducta, las sensaciones y los estados de conciencia. Muchos fenómenos de la experiencia sensible dejarían de tener el sentido actual, pues carecerían de espontaneidad y novedad, ya que podrían ser programados. ¿Qué pasaría con las relaciones entre emociones y sentimientos éticos? ¿Podríamos programar que los individuos sintieran solidaridad, compasión, fraternidad? O, por el contrario, ¿programarlos para no sentirse vinculados emotivamente y poder atacar y matar con mayor eficacia?

10 Ello podría implicar una mutación radical de la relación humana con la muerte. No nos haríamos inmortales, pero sí podríamos crear la imagen de una des-senectud, una dislocación del ritmo vital que enrarecería la muerte «natural» al convertirla en un fenómeno evitable; pero a medida en que fueran efectivos el combate a la enfermedad, al envejecimiento y el retraso de la muerte, nadie sería sano naturalmente; y la muerte «natural» sería más bien un accidente. 
rediseño del cuerpo y de la conciencia humanos, así como en la manipulación del genoma mediante la inserción de genes de otras especies, con la finalidad de potenciar algunos procesos o crear nuevas propiedades y capacidades. Asimismo, el desarrollo de neurotecnologías encarnadas o protésicas podrían generar modificaciones sorprendentes e inéditas en la historia humana.

El desafío consiste en que desde ahora la tecnociencia tomaría la integridad del ser humano por objeto de transformación radical, y ello suscita asombro, pero también un temor social que no puede ser desatendido: ese poder que ahora nos sobrepasa y nos humilla con ostentosa perfección ha hecho que la imagen simbólica de lo humano aparezca como algo «obsoleto» y riesgosamente difuso.

Es este el sentido de la «obsolescencia» del hombre ante sus propias creaciones tecnológicas que Günther Anders planteaba (Anders, 2011). El ser humano se percibe a sí mismo más imperfecto, más precario, más vulnerable, sin estar a la altura del mundo tecnológico que ha construido. Este sentimiento de vergüenza prometeica, como lo llamaba Anders, refuerza la imagen de una naturaleza humana carente y defectuosa, pero perfectible y remediable biotécnicamente. Anders señalaba que la humanidad no se habría sentido hasta ahora tan poca cosa ante sus creaciones y, a la vez, tan prepotente y tan libre para superar su propia naturaleza imperfecta.

Debemos cuestionarnos si este desvanecimiento paulatino de la imagen simbólica de lo humano (algunos han anunciado la «muerte del hombre») representa un signo alentador que anuncia una era de plena emancipación y expansión de la libertad autopoiética, o bien un peligro inminente de destrucción de nuestra propia integridad biológica, debido a la incapacidad para reconstruir una imagen simbólica de lo humano de verdadero alcance universal. Como Jorge Riechmann ha señalado (Riechmann, 2004), la humanidad se está volviendo antropófuga, quizá resiente el peso de la mortalidad, de la contingencia y de la imperfección, además de cargar con cierta culpa por los desastres ambientales que ya no sabemos cómo resolver. Hannah Arendt ya atisbaba los síntomas del deseo de escapar de nuestra condición humana y de fugarnos también de la prisión espacio-temporal de la Tierra:

Este hombre futuro, que los científicos fabricarán antes de un siglo [...], parece estar poseído por una rebelión contra la existencia humana tal como se nos ha dado, gratuito don que no procede de ninguna parte, que desea cambiar por algo hecho por él mismo. No hay razón para dudar de nuestra capacidad para lograr tal cambio, de la misma manera que tampoco existe para poner en duda nuestra actual capacidad de destruir toda la vida orgánica de la Tierra. La única cuestión que se plantea es si queremos o no emplear nuestros conoci-

Véase en el libro El próximo paso. La vida exponencial, el capítulo de Aubrey de Grey «revertir el envejecimiento» (BBVA \& Open Mind, 2016). 
mientos científicos y técnicos en este sentido, y tal cuestión no puede decidirse por medios científicos; se trata de un problema político de primer orden y, por tanto, no cabe dejarlo a la decisión de los científicos o políticos profesionales. (Arendt, 1993, p. 6).

Cabe preguntarnos, desde una duda renovada acerca de nuestro propio ser, si la ampliada capacidad tecnocientífica de intervención en el cuerpo humano, ${ }^{11}$ fundamentan la posibilidad de una eugenesia tecnológica, y no solamente «ideológica», capaz de crear diferencias y distancias extremas no sólo simbólico-culturales, sino también físicas y biológicas, entre los seres humanos, y de amenazar nuestras concepciones universalistas sobre los derechos humanos (quizá la única lingua franca moral que poseemos hoy en día). La capacidad de intervención tecnocientífica para modificar estructuralmente el cuerpo humano y para revolucionar la relación entre el individuo y su medio tendría repercusiones radicales en la «ética de la especie humana» (Habermas, 2002), que debemos evaluar y analizar, más que contemplar pasivamente. La duda puede sembrarse: ¿la eugenesia positiva y el transhumanismo, una vez que alcanzaran logros efectivos, implicará alteraciones esenciales de la naturaleza humana?, ¿darán lugar a una transmutación biológica y ontológica de la humanidad, más allá de todas las transformaciones conocidas por nuestra especie en su largo proceso evolutivo?

Así pues, debemos enfrentar el desafío: repensar la naturaleza humana y generar las condiciones para una transformación biotecnológica que salvaguarde la continuidad de la herencia histórica, moral y cultural, así como la propia herencia biológica y genómica. Sabemos que la condición ética depende de la naturaleza humana, pero ahora la preservación de la naturaleza humana depende de la ética. Tenemos que reescribir una «ontología fundamental» en tiempos de penuria existencial/ abundancia técnica a la luz de los descubrimientos tecnocientíficos y de las posibilidades de transformaciones eugenésicas para reavivar el debate sobre nuestra propia naturaleza.

La imagen de la condición humana como ser simbólico e histórico, con la que el hombre parecía haber encontrado un sitio propio en el universo, puede estar en riesgo. Pues la humanidad podría entregarse a otro poder muy tentador abandonando la proyección simbólica de su ser: es el poder tecnológico de transformación e intervención en las estructuras mismas de la vida. Para

11 Entre otras posibilidades biotecnológicas para un futuro «transhumano» están la ingeniería de «enriquecimiento» genético (mediante la adición de genes exógenos a nuestra especie), el diagnóstico de preimplantación para seleccionar caracteres genéticos en los embriones, la clonación con fines reproductivos, la nanotecnología que crearía nuevos materiales que sinteticen lo electrónico y lo biológico, las prótesis biónicas, los neurofármacos y prótesis neurales, la inteligencia artificial, y quizá también la realidad virtual y otras tecnologías informáticas que alterarían radicalmente las funciones cognitivas principales (percibir, imaginar, recordar y pensar). 
que este poder tecnológico no escape de nuestro control es preciso asegurar la continuidad del otro poder humano: la simbolización individual y colectiva de un ser común, de un proyecto de humanidad.

En consecuencia, la ética para el mundo (bio)tecnológico (Linares, 2008) tiene que mediar entre la esfera de las libertades individuales (la esfera de la vida privada, en la que cada individuo debe decidir sus propios fines en función de su idea de vida buena) y la esfera de las condiciones y rasgos comunes a nuestra naturaleza biocultural. Esto es, requerimos principios mínimos que salvaguarden la libre autodeterminación de las personas, así como la diversidad de moralidades y de formas de vida que existen en las sociedades contemporáneas; pero también normas mínimas (universales o transculturales) que regulen y delimiten los alcances de las decisiones personales para proteger el patrimonio de la especie humana: el genoma y la configuración natural del cuerpo y del cerebro, así como su relación equilibrada con el medio ambiente.

No existe, pues, ningún límite físico para la automutación de nuestra especie, sólo podremos anteponer un límite ético-político. La herencia genética y la configuración corporal de nuestra especie deben ser resguardadas, no porque su estado natural sea bueno en sí mismo, sino porque la base biológica de nuestro ser ha constituido el sustento de la libertad y la autonomía; pero son vulnerables y están por ello encomendadas a nuestro cuidado, y nos imponen, desde esa conciencia, el deber de su preservación.

\section{El deSAFÍo DE LA ACTUAL IMAGEN AUtopoiÉTICA DE LA HUMANIDAD}

Los seres humanos pueden perder la memoria y la conciencia sobre la forma en que se ha construido este nuevo mundo que preconizaron las info, neuro, nano y biotecnologías; en él, la necesidad natural ha sido sustituida por una nueva modalidad de necesidades artefactuales. La humanidad ha emprendido desde sus orígenes la batalla para liberarse de la necesidad natural, pero ha pagado un precio muy alto por ello: debe ahora someterse y adaptarse a las condiciones del nuevo entorno tecnológico global que domina el mundo de la vida, que le es próximo por ser racional, pero ajeno por no ajustarse a las estructuras y condiciones históricas en que discurría anteriormente la existencia humana.

Sin embargo, el acelerado cambio tecnológico de principios del siglo XXI implica que nuestra especie debe hacerse, por primera vez, enteramente responsable de su destino. La humanidad se ha hecho relativamente autónoma frente a las determinaciones que impone la naturaleza; intenta resistir y ganar la batalla contra las limitaciones naturales del ciclo vital y de la muerte, que por milenios han sido una constante para el desarrollo de la humanidad; intenta asimismo reconfigurar el espacio y trastocar el orden sucesivo del tiempo. El mundo tecnológico que nos envuelve como una red de posibilidades ya no se ciñe a la condición natural de lo humano, sino que puja por conducir a la humanidad hacia 
un punto de no retorno, más allá de su condición natural. Pero lo que resulte de este formidable esfuerzo tecnológico, en el que los sueños y las pesadillas de todos encuentren su realización, será enteramente responsabilidad de los actuales agentes humanos del destino. Decisiones para las que aún no estamos preparados, pero ante las cuales deberemos asumir plena responsabilidad por el futuro incierto y ambiguo de nuestra especie. Nunca antes tuvimos tanto poder para superar nuestra condición natural, pero nunca antes estuvimos tan confundidos sobre el rumbo de nuestra existencia colectiva, como Ortega ya lo señalaba en su Meditación de la técnica (Ortega y Gasset, 2015).

\section{CONCLUSIÓN}

Ha surgido en nuestra era tecnológica una insospechada dimensión de la responsabilidad humana ante el porvenir ambiguo de nuestra existencia futura. Desde luego, no dispondremos de una idea definitiva e inmutable acerca de la naturaleza humana y del sentido de su historia evolutiva, porque nunca la hemos tenido y porque esta imagen simbólica es dinámica y líquida. Pero los efectos paradójicos de nuestros proyectos tecnocientíficos actuales de transformación y superación radical de la naturaleza humana, que surgen de la imagen antropotécnica de nuestra especie, deben conducirnos a una reflexión cuidadosa para evaluar y sopesar, mediante la precaución y la prudencia colectivas, dichos proyectos analizando sus probables consecuencias. De este modo, podremos recobrar la conciencia sobre nuestras profundas contradicciones, que quizá nunca podremos desterrar. La tensión esencial entre nuestra naturaleza mortal, finita, biológica y contingente y nuestra aspiración a superar dichas «limitaciones» para trascender en el tiempo y lograr el autocontrol de nuestra especie.

Un presentimiento se cierne entre estas ideas: es la sensación de experimentar un vacío ético ante los desafíos que enfrentará la humanidad en el mundo tecnológico que hemos creado. El vacío ético se produce en el «desfase prometeico» del que hablaba Anders. Ya no somos capaces de imaginar qué es lo que podemos producir en nuestros afanes de transcendencia y superación de la condición humana con la que venimos al mundo. Es el vacío de no tener respuestas adecuadas, y menos las tendremos si no nos comprometemos con una reflexión serena, ni ingenuamente entusiasta ni catastrofista, sobre los fenómenos actuales que afectarán la estructura ontológica del mundo de la vida $\mathrm{y}$, con ello, las condiciones en las que la humanidad proyectó y simbolizó su propia existencia y su incierto destino en la Tierra.

Huelga decirlo: el espejo enterrado de la identidad sigue sin darnos respuestas. 


\section{REFERENCIAS BIBLIOGRÁFICAS}

AGAR, N., 2010. Humanity's End. Why we should reject Radical Enhancement. Cambridge, MA.: The MIT Press.

ANDERS, G., 2011. La obsolescencia del hombre, vol I. Valencia: Pre-textos.

ARENDT, H., 1993. La condición humana. Barcelona : Paidós.

BBVA \& OPEN MIND, 2016. El próximo paso. La vida exponencial. Madrid: Turner.

DIÉGUEZ, A., 2017. Transhumanismo. La búsqueda tecnológica del mejoramiento humano. Barcelona: Herder.

GOFFETTE, J., 2006. Naissance de l'anthropotechnie. De la médicine au modelage de l'humain. París: Vrin.

GONZÁlEZ VALERIO, M.A. 2014. Prós Bín. Reflexiones naturales sobre arte, ciencia y filosofía. México: Universidad Nacional Autónoma de México.

HABERMAS, J., 2002. El futuro de la naturaleza humana. Barcelona: Paidós.

HARAWAY, D. J., 1995. Ciencia, cyborgs y mujeres. La reinvención de la naturaleza. Valencia: Cátedra / Universidad de Valencia.

HOTTOIS, G., 2002. Species technica. París: Vrin.

LINARES, J. E., 2008. Ética y mundo tecnológico. México: UNAM-FCE.

MORIN, E., 2003. El método V. La humanidad de la humanidad. Madrid: Cátedra.

NAGEL, T., 2000. Ensayos sobre la vida humana. México: Fondo de Cultura Económica.

NICOL, E., 1974. Metafísica de la expresión. segunda versión ed. México: Fondo de Cultura Económica.

___ 1977. La idea del hombre. segunda versión ed. Mexico: Fondo de Cultura Económica.

___ 1981. Historicismo y existencialismo. 3a. ed. México: Fondo de Cultura Económica.

ORTEGA Y GASSET, J., 2015. Meditación de la Técnica. Madrid: Biblioteca nueva. PLATÓN, 2011. Fedón, Banquete en Platón I, Madrid: Gredos.

RIDLEY, M., 2004. ¿Qué nos hace humanos?. Madrid: Taurus.

RIECHMANN, J., 2004. Gente que no quiere viajar a Marte. Ensayos sobre ecología, ética y autolimitación. Madrid: Libros de la Catarata.

SAVUlESCU, J. \& BOSTROM, N., 2009. Human Enhancement. Oxford: Oxford University Press.

SCHAEFFER, J. M., 2009. El fin de la excepción humana. Buenos Aires: FCE. 
Jorge Enrique Linares Salgado Es profesor titular de la facultad de filosofía y letras de la Universidad Nacional Autónoma de México

Pertenece al Sistema Nacional de Investigadores (CONACyT): Investigador nacional, NIVEL II. Es Miembro regular de la Academia Mexicana de Ciencias, de la Asociación Filosófica de México y de la International Association of Bioethics.

En 2004 obtuvo el grado de doctor en Filosofía por la UNAM y es profesor de tiempo completo en la Facultad de Filosofía y Letras de la misma Universidad desde 1996. Su trabajo de investigación y docencia se concentra en temas de Ética de la Ciencia y la Tecnología, Bioética y Ética contemporánea.

Ha recibido las siguientes distinciones:

En 2008, la Distinción Universidad Nacional para Jóvenes Académicos de la UNAM en el área de investigación en humanidades.

En 2007, el Premio Nacional de Filosofía de la Asociación Filosófica Mexicana por su tesis doctoral, titulada «Principios de una ética para el mundo tecnológico».

Publicaciones recientes:

Linares, J. y Arriaga, E. (coords.) Aproximaciones interdisciplinarias a la bioartefactualidad, México, UNAM, 2016.

González, J. y Linares, J. (coords.) Diálogos de bioética, FCE-UNAM, México, 2014,

Linares, J. Ética y mundo tecnológico, FCE-UNAM, México, 2008.

Dirección postal

Facultad de Filosofía y Letras

Universidad Nacional Autónoma de México

Email: lisjor@unam.mx 
